\title{
Noroeste da África - Nordeste do Brasil (Província Borborema) Ensaio comparativo e problemas de correlação
}

\author{
Benjamim B. Brito Neves ${ }^{1}$; William R. Van Schmus²; Allen H. Fetter ${ }^{3}$ \\ ${ }^{1}$ Departamento de Mineralogia e Geotectônica - Instituto de G eociências - USP \\ Rua do Lago 562, CEP 05508-900, São Paulo, SP \\ ${ }^{2}$ University of Kansas, Lawrence, Department of G eology, Kansas, USA \\ IInstituto de Geociências e Ciências Exatas - UNESP, Rio Claro, SP
}

Palavras-chave: Província Borborema, Colagem Brasiliana, Panafricano, Ciclo Cariris Velhos, Schist belts nigerianos.

\section{RESUMO}

A correlação geológica entre as porções Noroeste da África e Nordeste do Brasil enfrentam ainda uma série de problemas, de natureza virtual e real. A falta de um Projeto Internacional de Correlação Geológica (PICG) voltada para este tema é um aspecto crucial.

O primeiro grupo de problemas compreende a heterogeneidade do conhecimento geológico (muitos trabalhos de circulação restrita) assim como a diversidade das escolas de pensamento científico envolvidas no tema. Progresso importante foi feito na década presente, incluindo mapas de reconstituição pré-deriva (para o Aptiano) e uma série de doutoramentos no Pré-Cambriano do Brasil e da África, fatos que motivaram os autores a fazer uma revisão no assunto.

A correlação entre os crátons de S. Luis-África Ocidental (norte) e S. Francisco-Congo-Kasai-Angola (sul) que delimitam todo o contexto orogênico Brasiliano-Panafricano é relativamente bem documentada. Dos pontos de vista litoestratigráfico e tectônico, esta correlação é razoavelmente confirmada. Estes crátons/blocos devem ter sido fragmentos maiores de um mesmo supercontinente do Mesoproterozóico Superior, no qual as colagens orogênicas Paleoproterozóicas eram muito importantes. Igualmente, o cinturão de orogenias que perlonga e delineia a periferia destes crátons apresentam problemas de correlação de pequena monta, tanto no caso do Médio Coreaú/Dahomeides-Pharusiano (ao norte) como no caso do Sergipano/Oubanguides-Lindiano. Os principais problemas são quanto aos sistemas orogênicos distais dos crátons, mais para o interior da trama Brasiliano-Panafricana.

Na parte mais ao norte da Borborema, ao norte do Lineamento Patos (Patos/Garoua) foi identificado um grande bloco de embasamento bastante retrabalhado no ciclo Brasiliano-Panafricano que foi considerado um terreno tectono-estratigráfico, fração do supercontinente Rodínia (como os crátons). Este bloco formado principalmente por rochas de alto grau contém diversos remanescentes esparsos de supracrustais proterozóicas ("schist belts") e se estende do noroeste do Ceará à zona costeira da Borborema e daí para o interior do Niger. Predominam ortognaisses paleoproterozóicos $(2,35 ; 2,15 ; 2,0 \mathrm{Ga})$ de variadas composições, com inserções locais de cálcio-silicáticas e rochas aluminosas, arranjados consoante complexo quadro lito-estrutural (Tansamazônico-Eburniano) que inclui alguns prévios núcleos arqueanos $(3,45 ; 2,8 / 2,6 \mathrm{Ga})$. Os remanescentes xistosos sobrepostos ("schist belts") são compostos de contextos vulcano-sedimentares do Paleoproterozóico Superior (Estateriano) e do Neoproterozóico (ca. 820; 730, 640-600 Ma), todos eles trabalhados e/ou retrabalhados pelas fases mais posteriroes do ciclo Brasiliano/Panafricano. Ainda que a idade dos "schist belts" nigerianos seja tema controvertido, os resultados obtidos nos homólogos brasileiros podem provisoriamente ser estendidos para a África.

Na parte mais central, na área entre os lineamentos Patos (Patos/Garoua) e Pernambuco/Nagaounderé, ou seja, o chamado "median shear corridor" a correlação permanece como um problema difícil. No lado brasileiro foi reconhecido uma faixa móvel Eo-neoproterozóica (Cariris Velhos), retrabalhada no Brasiliano, e que parece parte do cinturão mundial de orogenias da colagem Grenvilliana. Há poucas evidências da presença desta faixa móvel na África até o presente. Adicionalmente, a correlação de faixas de supracrustais neoproterozóicas (excelentes exposições no Brasil) é difícil, devido a exposição rarefeita e em níveis crustais mais profundos no lado da África. 
Keywords: Borborema Province, Brasiliano Collage, Cariris Velhos Cycle, Nigerian Schist Belts.

\section{ABSTRACT}

The geological correlation between Northwest Africa and Northeast Brazil faces a series of problems of both virtual and real natures. The lack of an IGCP (International Geological Correlation Program) on this subject is a crucial aspect. The first group of problems encompasses the heterogeneity backgrounds of geological knowledge (much of which is in papers of restricted circulation) as well as the diversity of scientific thought in the schools involved with this problem.

Recent improvements in pre-drift (Aptian) paleogeographic maps, and a series of new PhD theses on the Precambrian shield in Brazil and Africa have stimulated the authors to review this theme.

The correlation between the large cratonic blocks that confine the Brasiliano-Pan-African System - São Luís- and West African cratons in the north and the São Francisco and Congo-Kasai-Angola cratons in the south - is relatively well assigned and reasonably constrained from the litho-stratigraphic and tectonic points of view. These crátons/blocks seem to have been major fragments of the same Mesoproterozoic supercontinent, in which Paleoproterozoic orogenic collage was very important. Similarly, the set of Neoproterozoic orogenic belts that delimitate external outlines of these cratonic nuclei presents only minor correlation problems for discussion, such as those to the north, as in the case of the Médio Coreaú/Dahomeyides-Pharusian belts, or those to the south, as in the case of Sergipano/ Oubanguides-Lindian belts.

The main problems concern the branching systems of orogens of the internal Brasiliano/Pan-African domains, distal to cratonic nuclei. North of the Patos (Patos-Garoua) shear zone in the northern part of the Borborema Province, a large basement block has been identified that contains several vestigial supracrustal belts ("schist belts"). It is considered a tectonic-stratigraphic terrane, former part of Rodinia (like the cratonic nuclei) and considerably reworked during Brasiliano - Pan African events. This reworked landmass mostly composed of high-grade rocks Paleoproterozoic $(2.35,2.15,2.0 \mathrm{Ga})$, orthogneisses of varied compositions, with minor insertions of calc-silicatic and aluminous gneisses, extends castward from NW Ceará to the Brazilian continental margin and, in Africa, from the coast far into the interior of Niger. This terrane displays a complex structural framework (Transamazonian/Eburnian) involving some small Archean nuclei $(3.45 ; 2.8$ / $2.6 \mathrm{Ga})$. Several scattered schist belts overlying this basement block are composed of volcanosedimentary sequences of Late Paleoproterozoic (Statherian) and Neoproterozoic (ca. $820 \mathrm{Ma}, 730$, 640-600 Ma) ages, all of them reworked during the last phases of the Brasiliano collage. Although the radiometric data for the schist belts of Nigeria are controversial, the recent set of Neoproterozoic data from Ceará and Rio Grande do Norte (Brazil) may be extended to Africa.

In the central part of the Borborema Province, between the Patos (Patos- Garoua) and Pernambuco/Ngaounderé shear zone systems ("Median Shear Corridor") correlation is still difficult. In the Brazilian territory an Early-Neoproterozoic (1000-960 Ma "Cariris Velhos") fold belt has been identified, which seems to be part of the worldwide framework of the Grenvillian collage. There is little evidence for this event on the African side, however. Additionally, correlation of Neoproterozoic fold belts well-exposed in Brazil is rather difficult due to the scattered record and deeper crustal nature of these supposed African equivalents.

\section{INTRODUÇÃO}

A correlação da Província Borborema (PB) com a porção Pan-Africana do Noroeste da África (Figura1 e Figura 2) tem sido tema de vários trabalhos anteriores, aqui referendados, mas é tema que ainda enfrenta uma série de problemas, alguns de ordem meramente virtual, para onde se espera a superação com o avanço e a integração do conhecimento geológico e geocronológico. O trabalho de Almeida (1965) é um dos mais remotos a ser destacado, e que primeiro considerou a fração de sistemas orogênicos da área entre o Togo e Gabão (panafricanos) como continuidade natural daqueles entre o noroeste do Ceará e a costa sergipana (brasilianos).

Entre estes problemas virtuais mencionados destacamse as diferentes equipes (francesa, belga, alemã, africanas de diversas nações e línguas) de trabalhos envolvidas com o tema, as diferentes escolas do pensamento científico (sobretudo no item geotectônica), a heterogeneidade da escala de conhecimento (válido também para a PB) das diferentes áreas. E, "last not least" a dispersão do conhecimento acumulado em ambos continentes, sem que haja no presente um esforço conjunto de análise e depuração desta massa crítica já constituída. A falta de um IGCP (International Geological Correlation Program) ou instituição similar é sentida, da mesma forma que se lamenta os resultados insatisfatórios e a condução e desfecho do último IGCP 108/144 (não chegou a nenhum resultado prático, nem a um relatório final). A situação política de algumas das várias nações africanas tem sido por algum tempo um óbice grande a levantamentos geológicos por equipes internacionais, mas se espera que isto venha a mudar. 


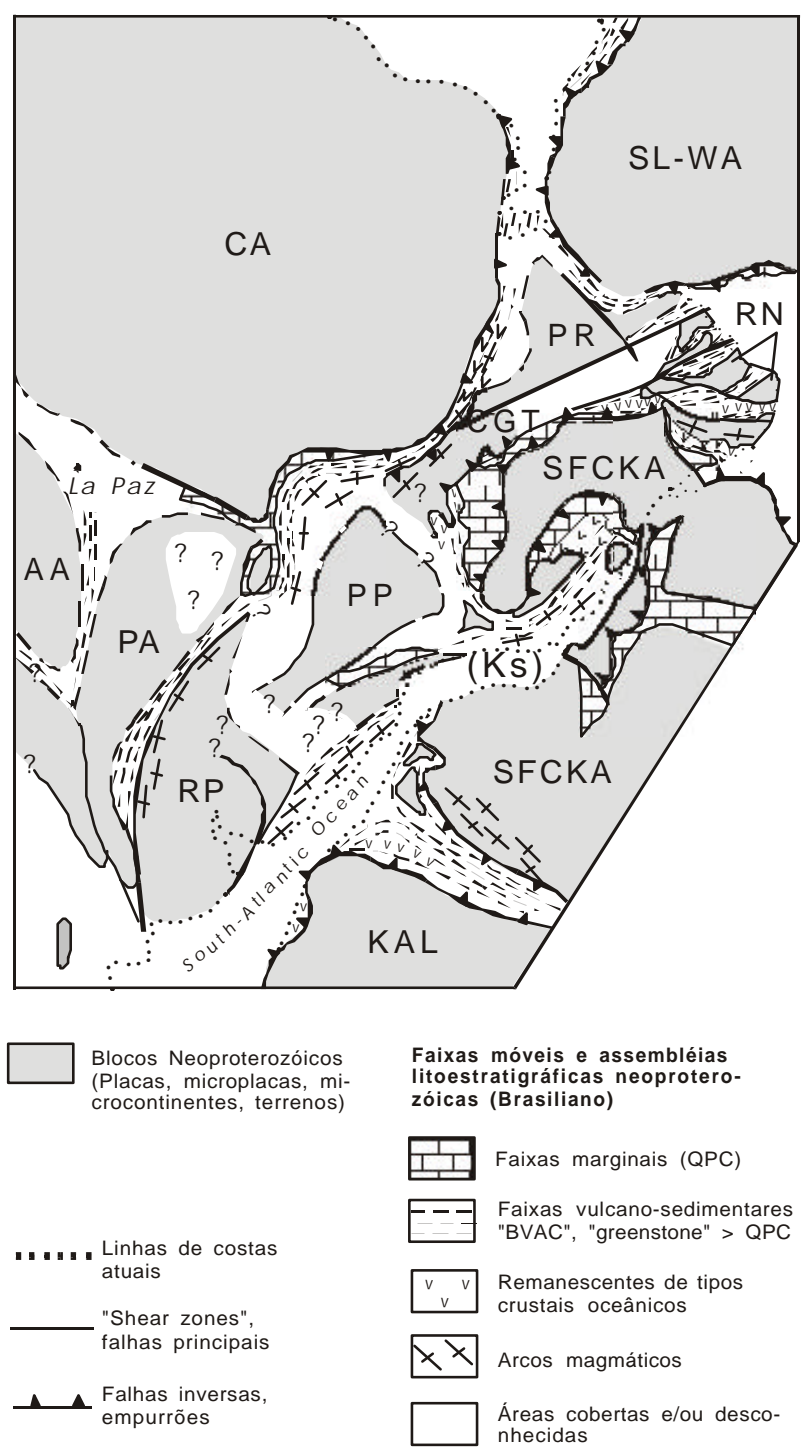

Figura 1: Mapa esquemático da paleogeografia final de Gondwana O cidental. Os descendentes neoproterozóicos de Rodínia (blocos/placas continentais, em cinza) e as principais faixas móveis resultantes da colagem Brasiliano Panafricana (BPA). Como mostrado, a área enfocada é o resultado da interação das placas/blocos CA (Cráton Amazônico), SL-WA (São Luis- África O cidental), PR (Parnaiba), SFCKA (São Francisco-Congo-Kasai-Angola) e outros blocos menores da Borborema. O bservação: RN = Rio Grande do Norte; PP = Paranapanema; Kal = Kalaári; RP = Rio de La Plata; PA = Pâmpia; $A A=$ Arequipa -Antofalla; CGT = Terreno Central de G oiás-Tocantins; Ks = Cretáceo Superior.

O recente mapa paleogeográfico pré-drift - (referente ao Aptiano) - elaborado pelo staff da Petrobrás (Matos, 2000, resumido na Figura 2), incorporando todo o acervo de dados de subsuperfície da província costeira e margem continental veio a solucionar um destes problemas virtuais e serve de estímulo para uma revisão do conhecimento no contexto do embasamento.
São considerados problemas reais a complexa configuração do embasamento da Província Borborema (PB), com seus "branched system of orogens" separados por "altos" do embasamento (chamados "maciços") de diferentes características estruturais e histórias evolutivas. $\mathrm{Na}$ contraparte africana, a história pós-drifte (após a fissão de Pangea) de individualização de continente foi contempla- 


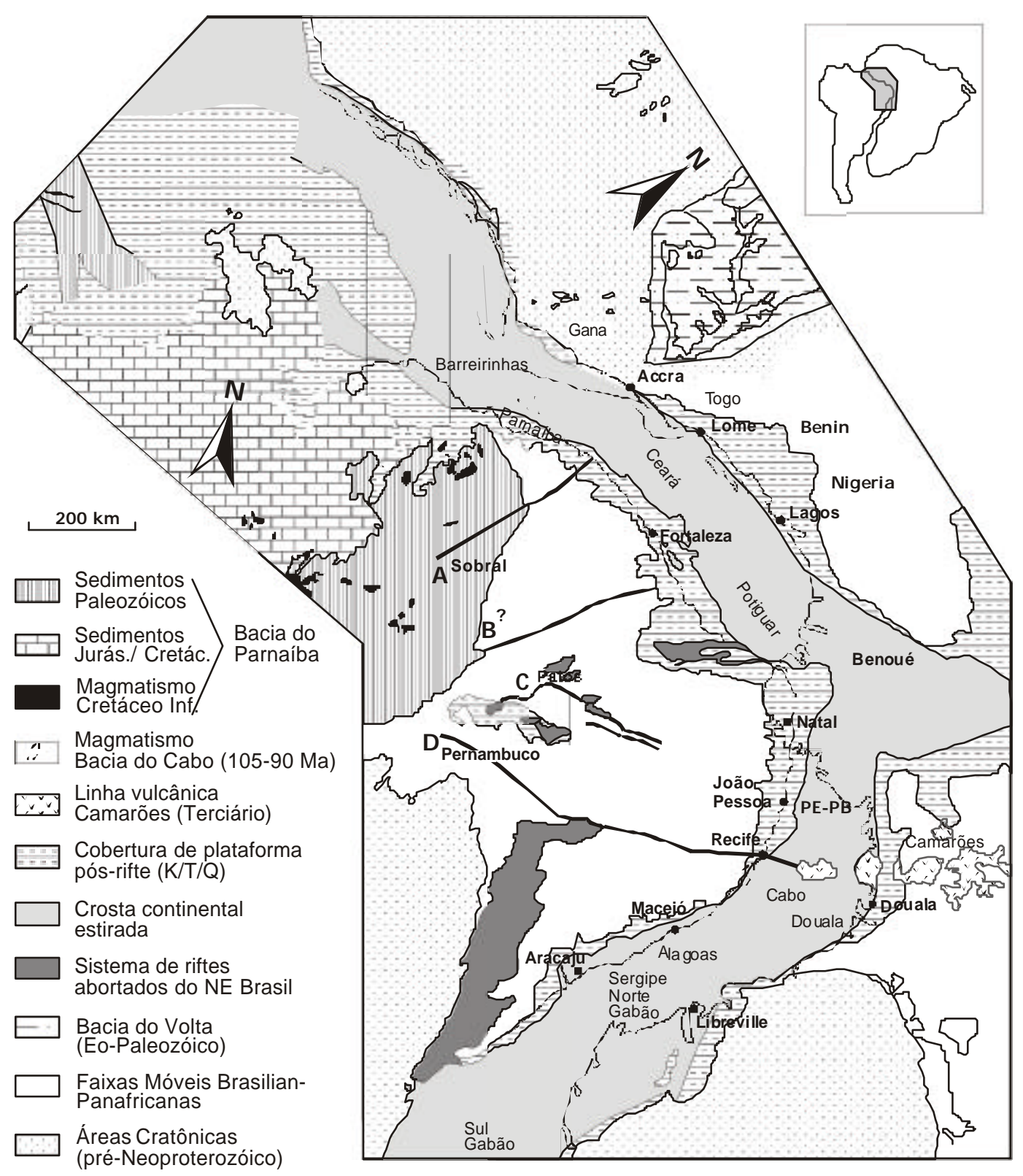

Figura 2: Reconstrução pré-drift (Período Aptiano) com o apoio de dados de subsuperfície das bacias costeiras e interiores, modificado de Matos (2000), dos arquivos da Petrobrás - RPNE, E \& P.

da com mais intensos e extensivos processos de desnudação erosiva, sendo comuns zonas de "schist belts", característicos de sistemas orogênicos vestigiais. Isto que já era típico e bastante divulgado para as áreas de escudo do Hoggar e da Nigéria (mais a norte e oeste), ficou agora também definido e de forma ainda mais drástica para a parte de Camarões (Toteu et al., 2000) ( Figura 3).

As coberturas sedimentares paleozóicas (Sinéclise do Parnaiba) e terciárias (tabuleiros costeiros) Barreira e
Camocim são óbices reais a serem defrontados, assim como a diferente evolução das linhas de costa dos dois continentes (e. g. progradação para oeste da costa africana, no delta do Niger). A isto se soma a evolução transformante da margem equatorial (estágio III do rifteamento) contraposta à evolução mais próxima do regime extensional simples (fases I e II do rifteamento) dos ramos intracontinentais (Tucano-Recôncavo) e centrais ("depressão afro-brasileira”, de Sergipe para o sul). De qualquer forma, à me- 


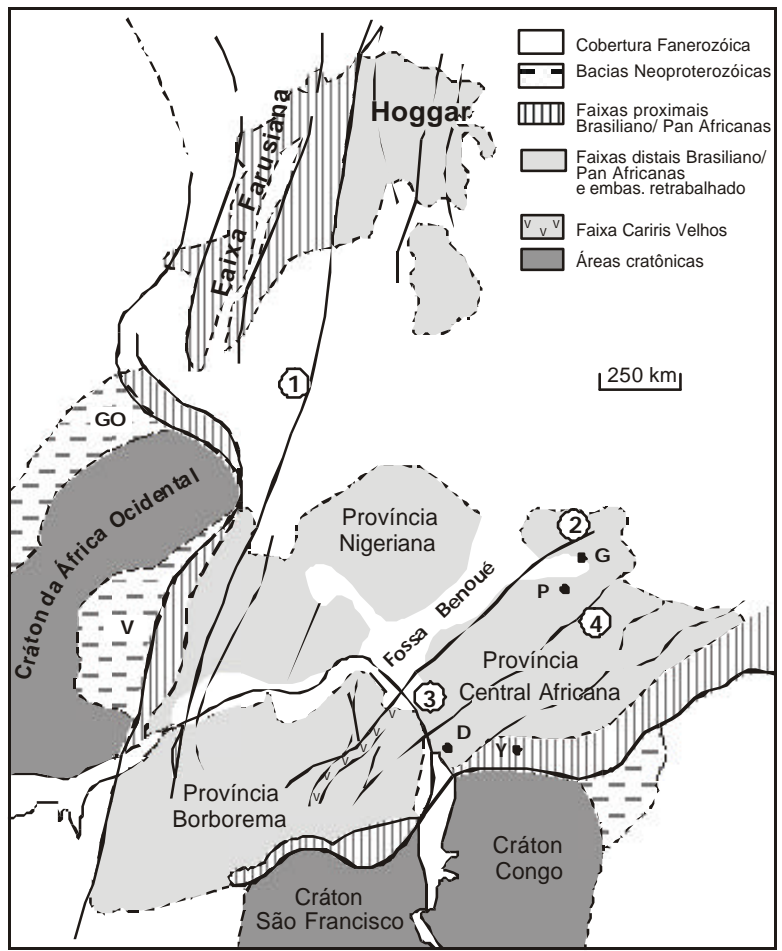

Figura 3: Mapa esquemático generalizado da geologia da África Central e 0 cidental e da Província Borborema, na configuração de Gondwana. Modificado de Castaing et al., (1993); Caby (1998) e Toteu et al., (2000).

1- Lineam. Kandi-Transbrasiliano; 2- Lin. Patos - G aroua; 3- "Median Shear Corridor"; 4 - Lin. PernambucoCamarões; Go - Bacia de Gourma; V - Bacia do Volta; PAS-Sutura Panafricana

$\mathrm{D}=$ Douala, $\mathrm{G}=$ Garoua, $\mathrm{Y}=$ Yaoundé, $\mathrm{P}=$ Poli, cidades nos Camarões.

dida que estas coberturas/bacias mesozóicas são melhor conhecidas, mais se ganha no conhecimento do embasamento, tendo em vista a íntima relação entre as estruturas ativadas e neoformadas com aquelas do substrato auferidas no Neoproterozóico.

Muitas teses (vide referências) foram desenvolvidas na última década nos dois continentes trazendo notável acervo de dados geológicos e enfoque direto ou indireto ao problema de correlação. Alguns trabalhos específicos de vários geólogos nesta última década, voltados para o arcabouço geral (e. g. Trompette, 1994; Caby e co-autores, em vários trabalhos sumulados em Caby, 1998; Castaing et al., 1993; Ledru et al., 1994) e outros com forte contribuição geocronológica (e. g. Bruguier et al., 1994; Toteu et al., 1994; Van Schmus et al., 1995; Dada, 1998; Toteu et al., 2000; etc.) constituem subsídios encorajadores de uma revisão no tema.

\section{QUADRO PALEOGEOGRÁFICO PRÉ- CAMBRIANO/PALEOZÓICO}

Como já mencionado, o recente mapa da situação aptiana pré-deriva da Petrobrás foi um elemento importante (Figura 2), a frente de vários outros de décadas anteriores pela escala maior e pelo respaldo na evolução da cobertura mesozóica, sua estruturação e dependência do "framework" Brasiliano-Panafricano (BPA).

De um modo geral, o contexto em análise - ora separado em dois continentes é considerado como fração de uma fusão supercontinental ("Gondwana Ocidental", Figura 1) no Neoproterozóico, arregimentando vários orógenos acrescionários e seus consequientes desenvolvimentos colisionais. Esta colagem orogênica foi à causa da aproximação e coalescência de alguns grandes blocos, como o São Francisco - Congo - Kasai - Angola (SFCKA), o São Luis-África Ocidental (SL-WA), o Parnaíba e o Rio Grande do Norte (RGND, vide Figuras 4 e 4a), e vários outros de dimensões menores ("maciços"). Esta aproximação e convergência causaram o fechamento de alguns braços de oceano (do grande oceano Neoproterozóico), como o Goianides, o Circum-SFCKA, o Adamastor, o ANEKT (Arábe-Nubiano-Etiópia-Quênia-Tanzânia e/ou Moçambique) e suas ramificações (Unrug, 1997; Brito Neves et al., 1999, entre outros) e a colagem orgênica se fez de forma diacrônica em diferentes estágios, da mesma forma como fora feita a desintegração/fissão do supercontinente (Rodínia) que antecedeu todo este quadro, que fora constituído no final do Mesoproterozóico.

O SFCKA e o SL-WA (Figura 1) são, no caso, os descendentes de maior dimensão de Rodínia, e os que mais preservaram suas estruturas originais, elaboradas na colagem do Paleoproterozóico (embora no S. Francisco haja faixas orogênicas mais jovens, do Mesoproterozóico Superior). Particularmente a porção brasileira (Cráton de São Luis) do SL-WA é uma fração de uma faixa móvel paleoproterozóica, com respaldo de um bom contingente de dados geológicos e geocronológicos recentes (Alvarenga et al., 2000) e que ao alcançar a plataforma continental suporta uma região larga e típica de embasamento sísmico raso conhecido como Plataforma de Ilha Santana. Os demais blocos, de dimensão intermediários e pequenos, embora retenham vestígios de sua filiação à Rodínia e à colagem paleoproterozóica (e simplistamente tutelada de "Transamazônica", o que parece indevido ou incompleto), foram completamente regenerados ao longo da história tectônica neoproterozóica dos ciclos Brasiliano-Panafricano (BPA). Esta regeneração implica em deformações a diferentes níveis crustais, "resetting" isotópico, penetração de ígneas, etc., ou seja 


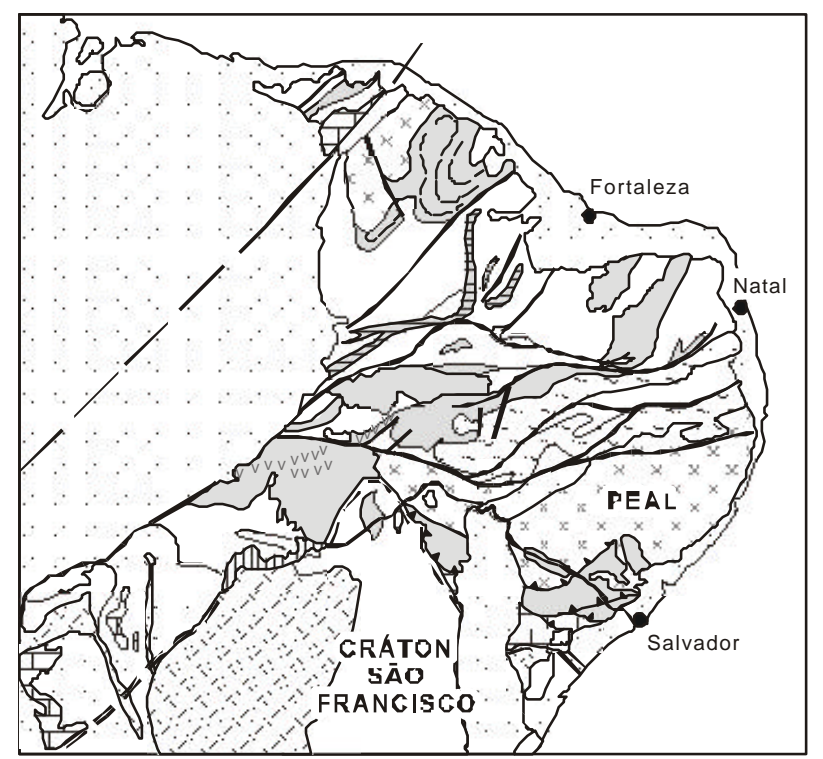

Coberturas fanerozóicas indiferenciadas FAIXAS BRASILIANAS

Assembléias vulcano-sedimentares neoproterozóicas

Assembléias vulcano-sedimentares do Paleoproterozóico Superior (Estateriano)

Associações lito-estruturais Meso-Neoproterozóicas retrabalhadas (Cariris Velhos)

Zonas externas, faixas pericratônicas (pelítico-carbonáticas) $\mathrm{vV}^{\mathrm{V}}$ Zonas internas, remanescentes de arcos e tratos oceânicos

X Zonas granítico-migmatíticas. Terrenos paleoproterozóicos e mesoproterozóicos retrabalhados

Coberturas cratônicas paleoproterozóicas e mesoproterozóicas, retrabalhadas

Embasamento paleoproterozóico (Núcleos Arqueanos locais)/ CSF=Craton São Francisco

$E==2$ Limites cratônicos

Falhas inversas, empurrões

Zonas transcorrentes e zonas de falhas

Figura 4: Esquema geológico geral da Província Borborema e nomenclatura usual para os "terrenos" (Figura 4A) que compõem a província (Brito Neves et al., 2000).

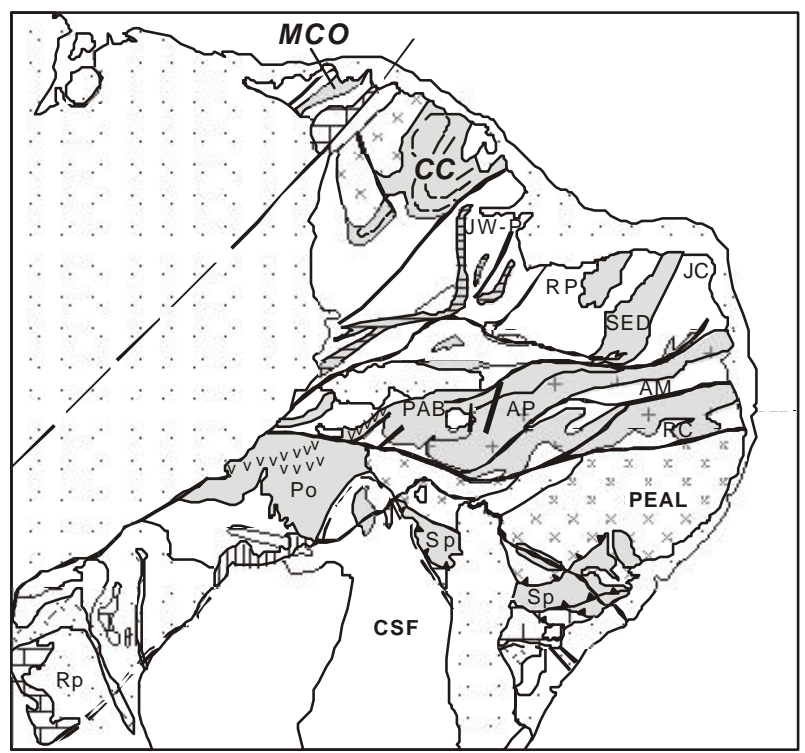

\begin{tabular}{|c|c|c|}
\hline $\mathrm{MCO}$ & & Médio Coreau \\
\hline$C C$ & & Ceará Central \\
\hline RGND & $\begin{array}{ll}\text { JW-P } & \text { Jaguaribe-W Potiguar } \\
\text { RP } & \text { Rio Piranhas } \\
\text { SED } & \text { Faixa Seridó } \\
\text { JC } & \text { São José Campestre }\end{array}$ & R. Grande do Norte \\
\hline$T Z$ & $\begin{array}{ll}\text { PBA } & \text { Piancó-Alto Brígida } \\
\text { AP } & \text { Alto Pajeu } \\
\text { AM } & \text { Alto Moxotó } \\
\text { RC } & \text { Rio Capibaribe }\end{array}$ & Zona Transversal \\
\hline $\begin{array}{c}S D \\
P E A L \\
\end{array}$ & $\begin{array}{ll}\text { Rp } & \text { Rio Preto } \\
\text { Po } & \text { Riacho do Pontal } \\
\text { Sp } & \text { Sergipano } \\
& \text { Maciço Pernambuco } \\
& \text {-Alagoas } \\
\end{array}$ & Domínio Sul \\
\hline CSF & & Cráton São Francisco \\
\hline
\end{tabular}

Figura 4 A: Nomenclatura usual para os "terrenos" que compõem a província (Brito N eves etal., 2000). 
na perda de características de área cratônica, como aquelas mantidas pelo SL-WA e SFCKA, apesar do intenso retrabalhamento às suas bordas. Parte da extensão pretérita destes núcleos cratônicos ocupa hoje posição na infraestrutura de BPA, em faixas proximais e mesmo distais, com intensidades de retrabalhamento distintas das da parte sul da Faixa Central Africana (também chamada de Oubanguides e sua extensão Lindiana). Apesar de algumas dificuldades de correlação devido aos problemas de níveis crustais expostos e outros de coberturas e modificações da linha de costa, estes são referenciais de correlação mantidos e orientadores dos demais.

Os problemas acrescem para as zonas distais destes domínios cratônicos, nas faixas mais distais e internas do BPA. Mas é possível distinguir subsidiariamente outros referenciais de correlação, agora na parte central do BPA, em estruturas geradas na fase final de sua evolução, sin a pós-colisionais. A Zona Transversal (AP, AM e RC, Figura 4A) da PB, entre os lineamentos de Patos e Pernambuco, que cinge e limita ao sul o Terreno Tectonoestratigráfico RGND, parece ter continuidade em África entre os lineamentos de Garoua (sul, sudeste de Benoué, incluindo alinhamento de depocentros lito-estratigráficos e de anomalias gravimétricas) e Adamaoua-Ngaounderé, este um "shear belt", do BPA, onde se instalou posteriormente a 'linha vulcânica terciária dos Camarões. Este corredor central (vide adiante na Figura 7), produto da tectônica extrusional do final do Neoproterozócio e do Cambriano, já esquematizado por Trompette (1994), e que vem sendo confirmado pelos dados mais modernos.

$\mathrm{Na}$ análise destas faixas e maciços, e na posição geológico-geotectônica dos mesmos nos dois continentes, apareceram outros pontos de amarra ("links", e. g. algumas zonas de cisalhamento comuns aos dois continentes) nesta tentativa de correlação, assim como as principais discrepâncias de conteúdo e de grau de exposição (nível crustal hoje), sejam eles originais (do Pré-Cambriano/ Paleozóico) ou adquiridos na história pós-drifte.

\section{A porção Ocidental do SL WA: Rokelides/Bassarides-Araguaia}

Embora a Faixa Araguaia não seja parte da Província Borborema (trata-se do ramo setentrional da Província Tocantins), seu encaixe na história pós-Rodínia e na evolução BPA (vide Figuras 1 e 3 ) é ponto de partida e entendimento do conjunto. A conexão dos ramos oceânicos do Rokelides com aquele do Dahomeyano é uma hipótese de trabalho, que não pode ser comprovada nem descartada ainda em face das muitas coberturas paleozóicas, mesocenozóicas do Rio Pará ao Rio Parnaíba. A conexão deste desenvolvimento oceânico desde a costa sudeste norteamericana (Dallmeyer, 1989) até o noroeste argentino (Ramos, 1988; Rapela et al., 1998) tem inúmeros trabalhos de apoio por toda a década recente, como já sumarizado por Brito Neves (1999).

Certamente, consoante tal estirão oceânico com cerca de $4000 \mathrm{Km}$ lineares, diversos tipos de tratos de embasamento sóem ocorrer (à semelhança do Oceano Iapetus, do início do Paleozóico). Assim sendo afloram núcleos arqueanos, de forma dômica, frações da colagem paleoproterozóica ("transamazônico"), coberturas vulcano-sedimentares do Paleoproterozóico Superior e do Mesoproterozóico, e mesmo trechos de faixas móveis do Mesoproterozóico Superior (Grevillianas e afins). Afora a linearidade e continuidade deste sistema, há várias compatibilidades de tempo e registro lito-estratigráfico e fases de tectogênese.

A história tectônica remonta aos $700 \mathrm{Ma}$ (rifting inicial), sedimentação de uma seqüência marinha plataformal, com variações para marinha profunda e localmente resquícios de fundo oceânico, a que se seguiu uma importante fase de deformação (chamada de Pan African I na África). A seguir se tem o registro de uma sedimentação marinha clástica, com presença de diamictitos de origem glacial e "red beds" e o fecho da tectogênese em torno de 575-550 Ma, com sobreposição de coberturas clásticas grosseiras de caráter molássico. As evidências são de que esta fase de fechamento foi cada vez mais jovem para o sul (na faixa de 520-530 Ma na Argentina, e mais jovem ainda para a Antártica). Da África Ocidental ao noroeste Argentino, as coberturas paleozóicas (Taoudeni, Parnaíba, Paraná-Chaco) privilegiaram esta faixa móvel. Interessante apontar que o registro lito-estratigráfico pré-cambriano é ainda pouco conhecido no Araguaia, e que este tipo de desenvolvimento tem muita afinidade com aquele da porção brasileiro-paraguaia da faixa móvel.

As vergências estruturais opostas - no Brasil para o Cráton Amazônico e na África para o SL-WA - apontadas como óbice ao problema de correlação não parecem insuperáveis, tendo em vista os diagramas de Lécorché et al. (1989) e Hasui et al. (1984), e outros dados geológicos e geofísicos. É preciso considerar a situação destas frações de faixas móveis como partes referentes aos domínios mais externos, de "foreland" (em condições "thin"e "thick skin") vergentes para os respectivos núcleos rígidos. As vergências opostas podem ser acomodadas num modelo de fechamento de um trato oceânico relativamente estreito com conseqüente expulsão de massas e transporte tectônico de forma centrifuga (Hatcher \& Williams, 1986) 
em demanda dos respectivos antepaises. A retomada hercínica observada na África (Mauritanides) teve também homologia no continente sul-americano, tendo em visto que toda a região do Pâmpia e faixas adjacentes foram retomadas nos processo orogênicos paleozóicos e mesozóicos.

\section{Trans-Sahara/Borborema Norte Ocidental}

\section{Porção 0 cidental (a oeste do lineamento Kandi-Transbrasiliano)}

A recente síntese de Caby (1998) sobre a parte mais ocidental do Trans-Saariano e as diversas teses geradas nesta década no noroeste do Ceará (Domínio do Médio Coreaú) permitem tratar da continuidade desta faixa orogênica - subducção seguida de colisão - como única, malgrado algumas especificações geradas na história tectônica e sedimentar subseqüente. Ou seja, admite-se a continuidade, reconhecendo-se alguns problemas, dificuldades e algumas defecções.

$\mathrm{Na}$ África, o registro deste desfecho orogênico é quase completo e comparável aos paradigmas fanerozóicos, tendo Caby (1998) (síntese de uma ampla seqüência de trabalhos de co-autoria de 20 anos) reconhecido cerca de onze elementos característicos do processo evolutivo de conversão de margem Atlântica para margem Pacífica, no Neoproterozóico. Parte destes elementos apenas pode ser reconhecida atualmente no lado cearense (Brito Neves et al., 2000), não obstante os muitos deslocamentos causados pela marcante tectônica disjuntiva extrusional desta porção do Ceará, adjacente a uma zona de cisalhamento de proporções extraordinárias. Há a possibilidade de que alguns outros daqueles elementos tectônicos mencionados por Caby (1998) em sua ampla revisão e estejam ocorrendo sob a cobertura paleozóica (Parnaíba, Jaibaras) e terciária (Barreiras, Camocim). A designação de cinturão de cisalhamento do Noroeste do Ceará, usada por alguns autores (vide Hasui et al., 1984) não é ideal, mas é chamativa para esta característica do quase completo mascaramento /destruição das feições clássicas de orógeno acrescionário seguido de colisão (como preservado em África).

Merece ser comentado que faltam evidências da margem continental passiva "subductada" (elemento 3 da enumeração de Caby, op. cit.), das bacias de retroarco (elemento 5) e arcos intraoceânicos ( elemento 6) que podem existir em subsuperfície, mas não há dados concretos ainda. Quanto à grande sutura de colisão traçada por Caby em África (elemento 9), ela não é observada no noroeste do Ceará diretamente, mas ela pode estar passando no embasamento da Bacia do Parnaíba, por uma seqüência linear de altos gravimétricos identificados no trabalho de Lesquer et al. (1984). Fica reiterado que é uma possibilidade a ser melhor explorada em escala de detalhe, não é um fato concreto, como assumido por Lesquer et al.(1984). Deve ser acrescentado que têm sido reconhecidos em subsuperfícies depósitos de antepaís (dados inéditos da Petrobrás), no lado brasileiro, daqueles tipos encontrados nas Bacias do Volta e Gourma, da borda do núcleo arqueano do ocidente da África.

Na detalhada descrição da Bacia do Volta de Affaton (1990) dos supergroupos Boumbouaka, Pendjari e Tamale ("molássico") são notáveis as semelhanças litológicas gerais com os depósitos da Bacia de Jaibaras e congêneres de subsuperfície (seguindo o "trende" do lineamento transbrasiliano na direção do Brasil Central, captados em subsuperfície por poços pioneiros), alocados em depressões transtrativas e outros tipos de riftes. Os fatores semelhança litológica (o Supergrupo Tamale principalmente), condicionamento tectônico e idade (dentro da escala de análise) são afins, o que são fatos ainda insuficientes para se falar de correlação litoestratigráfica - mas que são convincentes no tocante à equivalência de ambientes tectônicos. A propósito, há uma tendência atual de se considerar a Bacia do Volta inteiramente molássica, do tipo "foreland" (informação verbal de R. Trompette).

Os valores de idade do processo evolutivo em ca. 850$800 \mathrm{Ma}$ (rifteamento original), orogenia em torno de 625$580 \mathrm{Ma}$, e eventos pós-colisionais (extrusão, bacias molássicas, granitogênese) ao redor de 520-545 Ma são coerentes nos dois continentes. Mais para o leste, no chamado contexto do "maciço de Santa Quitéria", Fetter (1999) (vide Figura 5 e Figura 6) identificou rochas tonalíticas e granodioríticas de caráter juvenil, geradas em ambiente de arco continental, datados de $622 \pm 4 \mathrm{Ma}$, que certamente não deve ser ponto exclusivo, e o que abre a possibilidade de para o futuro virem a ser identificados contextos de subducção menos evoluídos e mesmo arcos intraoceânicos como na África. No exame da Tabela 1 devem ser discriminados os eventos de "orogênese precoce" (0, 87- 0,84 Ga, de Caby, 1998) e Pan-Africano inicial (0,75-0,70 Ga, de Caby, 1998), relativamente bem diagnosticados na África que não foram ainda identificados no lado brasileiro, e a Tabela 1 tenta enfatizar este fato. Mas, devido ao estágio precário do conhecimento geológico do estado do Ceará e da sua extensa área (com muitas supracrustais e rochas graníticas ainda intocadas do ponto de vista geológico e geocronológico) tem de ser ter uma atitude de expectativa em relação a estes dados, ao invés de formalizar uma distinção nesta primeira instância. 


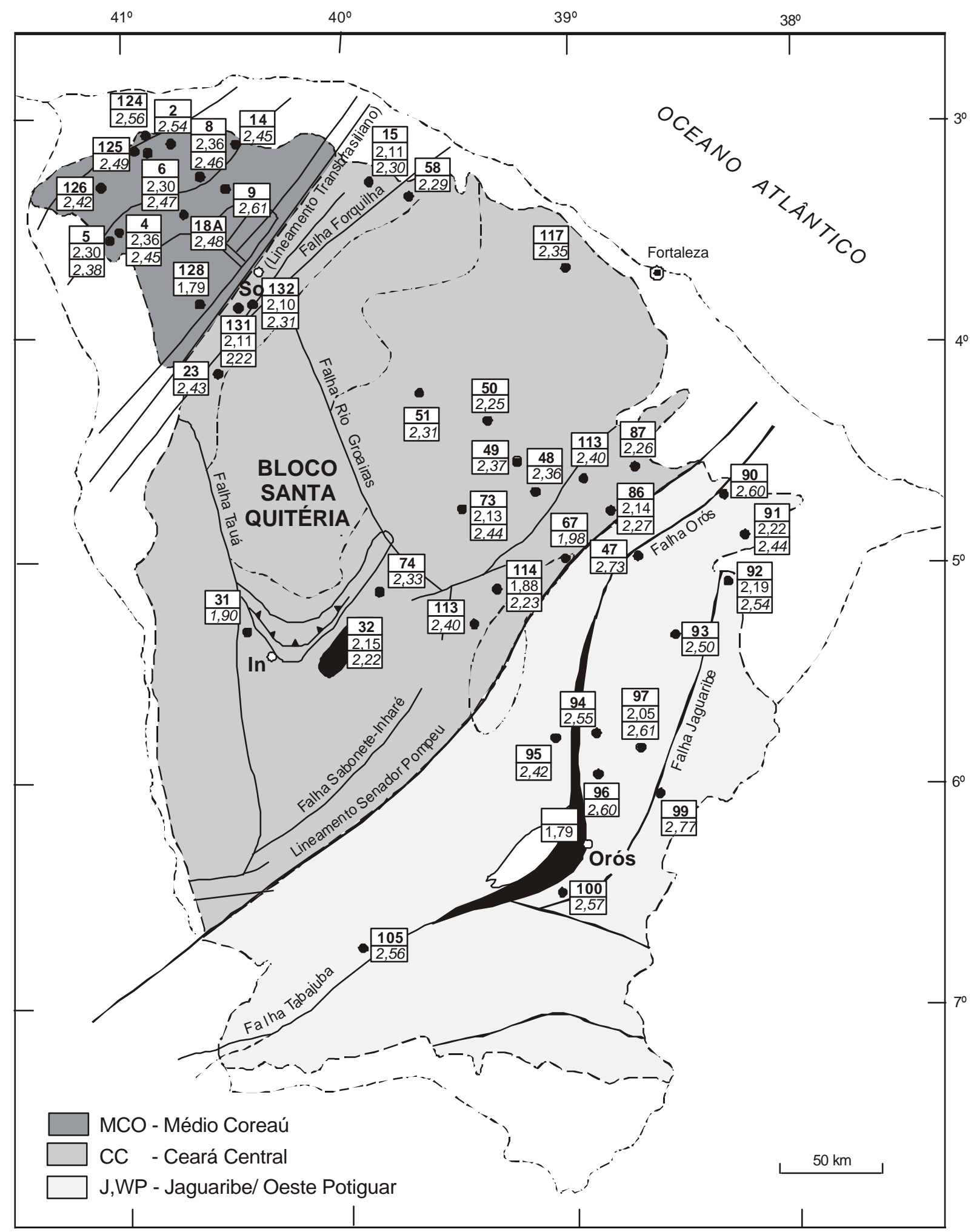

Figura 5 : Visão geológica geral do Estado do Ceará e destaque para os seus três principais domínios crustais: MCO = Médio Coreaú (oeste do lineamento Kandi-Transbrasiliano), CC = Ceará Central, J-WP = Jaguaribe- O este Potiguar, parte ocidental do RG ND). Dados isotópicos recentes de Fetter (1999) a saber: em negrito: número de ordem; em preto e branco normal: idade U/Pb em zircão, para embasamento e supracrustais; em itálicos: valores de idade Tdm (método Sm- $\mathrm{Nd}$ ). 


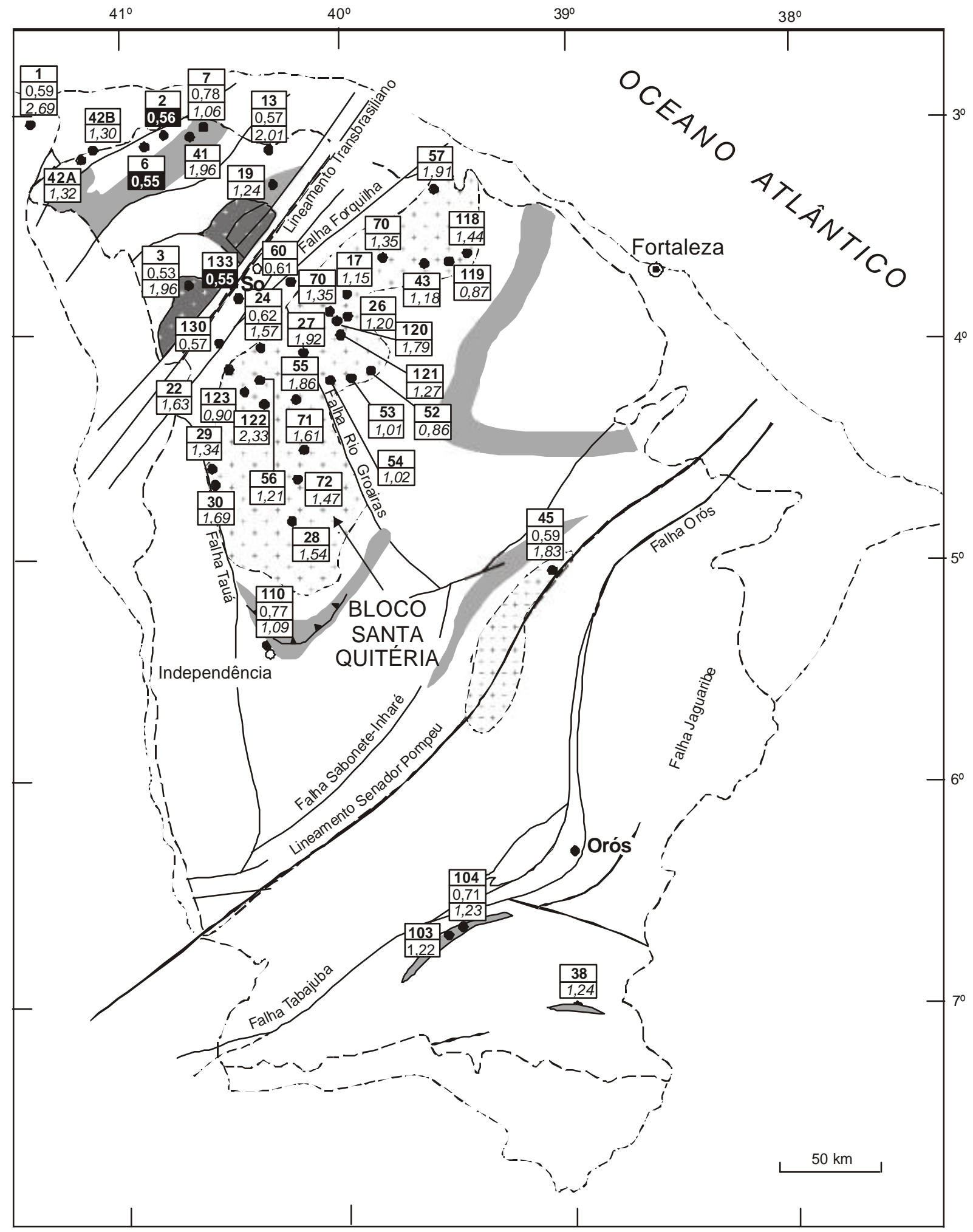

Figura 6: Visão geológica do Estado do Ceará com ênfase para as rochas neoproterozóicas (em cinza). Consoante com determinações recentes de Fetter (1999): supracrustais do MCO, rochas graníticas do "Maciço Santa Quitéria" (arco Neoproterozóico?) e das faixas de supracrustais do Médio Coreaú (a noroeste), de Independência - Rio Curu e Jaguaribeana. Em negrito: número de ordem; em branco e preto normal: idades U/Pb em zircão para supracrustais e graníticas; em itálicos, valores de idade $\mathrm{Tdm}$ (método $\mathrm{Sm}-\mathrm{Nd}$ ); em preto com letras brancas: idades de resfriamento (U/Pb em titanitas). 
No tocante às coberturas fanerozóicas, há uma diferença interessante a assinalar. Em vários dos perfís da Bacia de Taoudeni apresentados por Goodwin (1991, p.526), aparecem unidades litoestratigráficas ordovicianas e a alusão a sedimentos glaciais neste período, o que são fatos desconhecidos no desenvolvimento do Parnaíba, cuja evolução é a partir do Siluriano.

\section{Porção 0 riental (imediatamente a leste do Lineamento Kandi-Transbrasiliano)}

Embora sejam caracteristicamente áreas vestigiais, com esparsa distribuição de supracrustais e amplas exposições de terrenos pré-BPA, as similaridades gerais entre os terrenos de alto grau das áreas de escudos do Hoggar Central e da Nigéria e aqueles do "terreno tectono-estratigráfico do Rio Grande do Norte "RGND" - disposto como porção setentrional da Província Borborema, ao norte do lineamento de Patos - são de várias ordens. Estas afinidades transcendem em muito o atual nível de conhecimento e somatória de dados geológicos gerais, petrológicos e geocronológicos, que de certa forma está resumido na comparação esquematizada na Tabela 1. Foi baseado em similaridades destes tipos, e desprezando algumas diferenças a considerar, que foi ousada uma designação conjunta de "Terreno Potiguar-Hoggar" para este contexto (Brito Neves et al., 1999), na presuposição de que se trataria de um único megafragmento do Supercontinente Atlântica, da concepção de Rogers (1996).

Merecem ser destacados os aspectos:

a. Embasamento constituído como fração da colagem paleoproterozóica, que envolveu pelo menos dois ciclos orogênicos: ca. $2150 \pm 50 \mathrm{Ma}$ e ca. $2000 \pm 50 \mathrm{Ma}$, e nos quais foram arregimentados e retrabalhados alguns núcleos microcontinentais paleoarqueanos (como Presidente Kubitschek e Kaduna), mesoarquenaos e neoarqueanos (Tróia-Tauá, Granjeiro-Várzea Nova, etc.). Este embasamento de alto grau foi recoberto por formações vulcano-sedimentares do Estateriano, seqüências de riftes e assemelhadas e foi cortado por granitos anorogênico de tendência alcalina. Os eventos de ca. 2150 Ma são importantíssimos no RGND, provavelmente definidores de uma colagem supercontinental (O "RGND" seria um megafragmento de um supercontinente, um "terreno tectono-estratigráfico" no sentido de Howell, 1995). Na África, referências sobre estes eventos de 2.150 Ma são raríssimos ainda (vide Tabela 1) o que é surpreendente, sendo possível que isto se modifique substancialmente com o incremento das determinações U-Pb em zircão.

b. Esta colagem paleoproterozóica inclui alguns tratos rochosos de 2,3-2,35 Ga tanto de geração (diferenciação manto-crosta, (idade $\mathrm{Tdm}$ em rocha total) como de recristalizados (intrusão e metamorfismo regional de alto grau, idades $\mathrm{U}-\mathrm{Pb}$ em zircão). Isto foi reconhecido neste âmbito do Sideriano, tanto no Noroeste do Ceará (Fetter, 1999) como na Nigéria (Dada, 1998), o que é uma peculiaridade digna de nota (vide Figuras 5 e 6).

c. Na África (no Hoggar, Adrar des Iforas) e no Brasil (praticamente toda porção centro-ocidental do RGND) são bastante bem representados os eventos da Tafrogênese do Estateriano (mais precisamente da parte mais superior deste período, entre 1,8 e 1,7 Ga), marcado por formação de bacias epicontinentais (vulcano-sedimentares) e plutonismo granítico (tipo A), discutidos por Brito Neves (1999) e Magini et al. (1999).

d. Alguns eventos locais, esparsos, tectono-termais, intrusivas máfico-ultramáficas, ocorrências de rehomogeneização e/ou perdas isotópicas de vulto, todos de natureza intracontinental (intraplaca) tomaram lugar por todo este contexto gnáissico-migmatítico orto e para derivado na passagem Mesoproterozóico-Neoproterozóico. Mas, de consignação esporádica, e provavelmente eventos reflexos de orogenias ocorrendo alhures ("foreland tectonics" relativa ao Cariris Velhos e afins) ou outros de natureza "autônoma", sub-litosférica. As indicações incluem a possibilidade de faixas orogênicas deste período do tempo, mas de eventos de interação ("reflexos") ocorrentes alhures.

e. No Neoproterozóico todo este contexto participou ativamente do desenvolvimento BPA, de diversas maneiras, primeiramente pelo desenvolvimento orogênico cujo farto registro supracrustal está descrito no ítem TransSahara, no Seridó (centro-leste do "RGND") e na zona transversal, mais ao sul. Mas, também pelo condicionamento de outros processos granitogênicos e mesmo orogênicos coetâneos e distais (e. g. "arco magmático de Santa Quitéria”, de Fetter, 1999; domínio "Tefedest Atakor", o "Tiririne belt", etc., vide Bertrand \& Caby, 1978). Granitos do desenvolvimento BPA ocorrem abundantemente por todo este contexto (sendo difícil configurar as rochas graníticas mais antigas, paleoproterozóicas). Em parte esta granitogênese está associada com falhamentos transcorrentes, e em parte pode ser creditada a espessamento crustal do terreno como um todo no BPA.

f. O papel das falhas transcorrentes no BPA é notável, desde a pré-organização dos diferentes domínios geológicos e geocronológicos (vide Figuras 1, 3 e 7), mas principalmente a na configuração de espectro final em análise. Estas falhas participaram também na tectônica formado$\mathrm{ra} /$ condicionadora de diversos sítios vulcano-sedimentares (e granitos), neoproterozóicos (e talvez outros mais antigos), hoje expostos como "schist belts" e faixas móveis, todas elas muito desfalcadas de termos lito-estratigráficos 
Ta bela 1: Tabela comparativa para os principais eventos/dados geológicos e geocronológicos disponíveis (ênfase para U-Pb em zircões, dados em Ga).

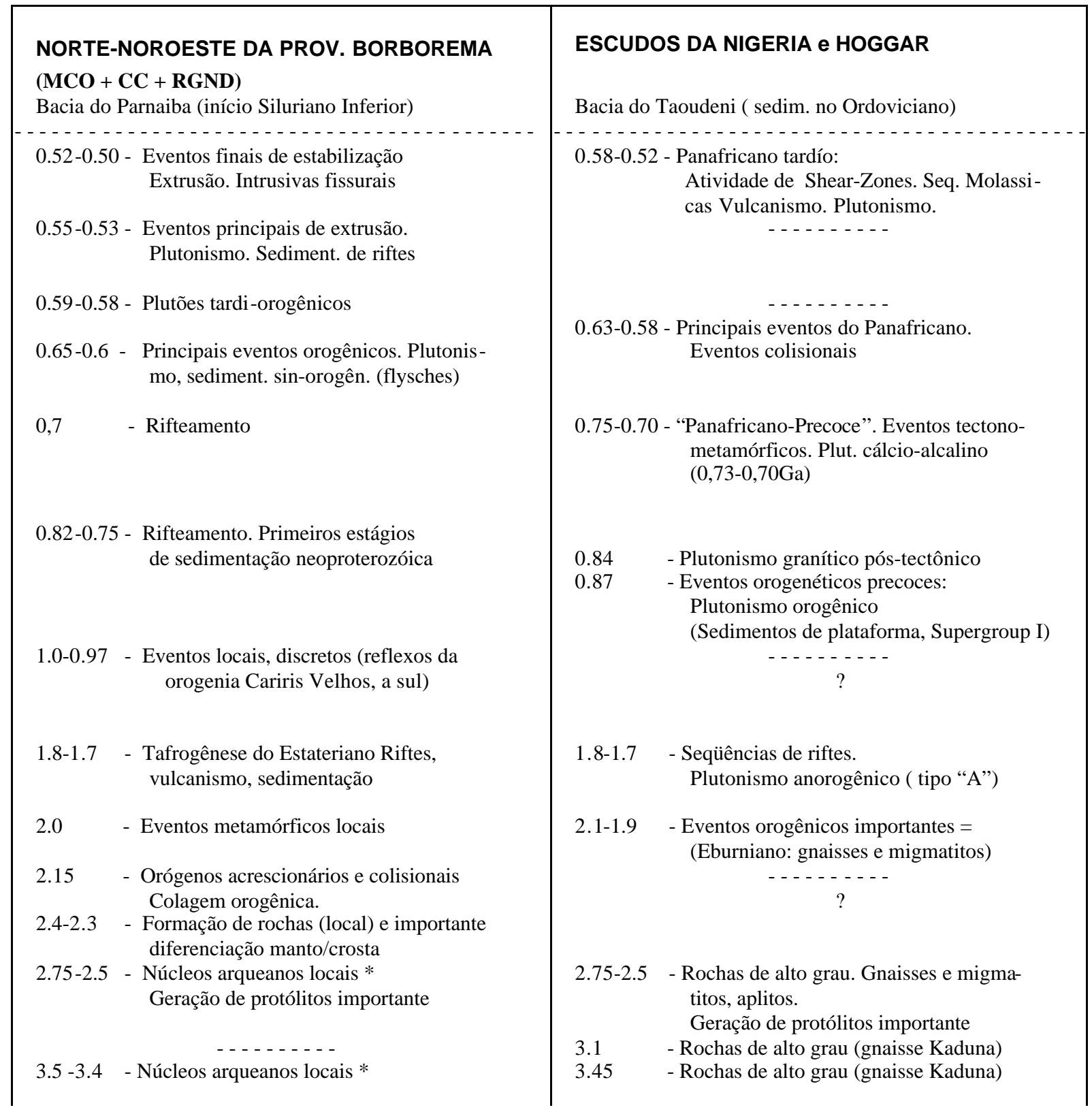

e outros, o que dificulta muito a análise de evolução. Interessante observar que alguns litotipos vulcanosedimentares do Estateriano passaram até mais de $1 \mathrm{Ga}$ como meras coberturas não dobradas ou moderadamente basculadas do interior "estável" e foram somente deformados no final do Neoproterozóico, em conjunto com outras unidades geradas nesta época, durante o BPA. g. Ainda que a idade dos "schist belts" nigerianos seja uma incógnita (Turner, 1983; Ajibade et al., 1987), muitos deles mostram características gerais de alocação e composição, com monótonas seqüências de quartzitos, metapelitos, cálcio-silicáticas, alguns carbonatos e vulcânicas subordinados, bastante semelhante (feições litológicas gerais, estratigrafia e condicionamento 
tectônico) àquelas descritas no Ceará por Arthaud et al., 1998. É bem possível, por analogia, que parte destas unidades seja do Estateriano (vulcano-sedimentares, como descrito no ítem a acima) e parte do Neoproterozóico. Correlações francas do tipo Iseyin Oyan/Ilesha (ocorrências das imediações de Ibadan) com aquelas da Faixa Jaguaribeana são possíveis , mas não foram ainda concretizadas. Da mesma forma que os xistos de Igarra (muito cobertos pelo delta do Niger) podem corresponder aos xistos do Seridó (neoproterozóicos), mas isto é uma tarefa para o futuro ainda.

Ainda que o quadro de semelhanças seja abonador, e de certa forma esteja realçado na Tabela 1, há algumas diferenças a serem reiteradas, tanto na evolução préCambriana (diferenças de fato já discutidas) assim como na evolução que sucedeu a separação continental (diferenças apostas). No tocante ao embasamento, Caby (1998) destacou diferenças importantes nos regime P-T nos processos de desnudação pós-orogênica ("descratonização"), no Hoggar Central, Nigéria e Ceará. A preservação da Faixa do Seridó no lado brasileiro, intracontinental, com notável acervo lito-estratigráfico (e seus recursos geoeconômicos) é outra diferença importante. Isto talvez tenha sido devido a maior intensidade dos eventos gliptogenéticos Pré-cambrianos e Fanerozóicos, destes últimos sobretudo, que foram realçados na Nigéria pela condição de se situarem nas ombreiras da Fossa de Benoué. Outras diferenças já foram comentadas, e estão realçadas na comparação da Tabela 1 .

Em se tratando do Fanerozóico, devem ser mencionados os granitos jovens da Nigéria, de idade jurássica que são uma característica de diferença marcante. Eles ocorrem nas duas áreas de escudo nigeriano (a norte a sul da Bacia de Bida, a nordeste da fossa Benoué) e poderiam ser simplesmente explicados como ligados a evolução do horst marginal a uma grande fossa. Mas eles não ocorrem no horst ao sul de Benoué (nem a sul da Bacia Potiguar no Brasil, nem em qualquer outro lugar destes continentes onde esperáveis). Adicionalmente, centros de vulcanismo terciário abundantes em África, muito bem expostos já nos esquemas de Popoff (1988) e Benkhelil (1989) e que se restringem a algumas ocorrências pontuais no lado brasileiro (na Bacia Potiguar e no agreste paraibano). Estas e algumas outras evidências mostram que houve desenvolvimento distinto pós-deriva das placas africana e sul-americana conforme já ficou mais evidente em muitos dos trabalhos apresentados no Colóquio de Geologia Africana de 1990, em Nancy, na maioria dos trabalhos ali apresentados.

\section{Zona Transversal/ “Median Shear Cor- ridor"}

\section{Caracterização e Feições G erais}

O Lineamento de Patos, mega-zona de cisalhamento destral de há muito definida teve um significado importante na PB, servindo de limite sul do terreno tectonoestratigráfico do Rio Grande do Norte (MCO+CC+RP+JC), considerado um fragmento de Atlântica, dentro do conceito de Howell (1995). E, desta forma, ocorre separando o contexto do RGND das Faixas Móveis do Ciclo Cariris Velhos (mais a sul, fragmento de Rodínia) e do Brasiliano (mais para sudoeste, fração da colagem PBA e de Gondwana). Em África, a continuidade deste lineamento é discutível face ao desenvolvimento sedimentar pós-deriva e progradação mascaradora para oeste da linha de costa (Delta do Niger). Mas diante da recente base de análise pré-deriva consolidada pela Petrobrás na Bacia Potiguar e rifteamentos adjacentes (Matos, 2000) e dos trabalhos de Popoff (1988) e Benkhelil (1989), já mencionados (entre muitos outros), é possível assumir que a continuidade deste lineamento está balizando ao sul a Fossa de Benoué.

Benoué é uma fossa singular, com tectônica formadora (Jurássico Superior/Oxfordiano) e deformadora (sobretudo do Cretáceo Superior), incluindo metamorfismo, ligada a movimentos transcorrentes da evolução da margem equatorial brasileira-africana. E este sistema de falhas foi implantado sobre descontinuidade disjuntivas preexistentes do embasamento, no prolongamento oriental do Lineamento de Patos. Além do melhor "fit" no esquema pré-deriva, esta direção $\left(\mathrm{N} 60^{\circ} \mathrm{E}\right)$ no continente africano é acompanhada por anomalias gravimétricas e magnetométricas lineares da borda sul da fossa, e por uma sucessão de depocentros alongados (cerca de cinco máximos) onde as isópacas atingem valores de até 5.000m ( Benkhelil, 1989).

No lado brasileiro a terminação oriental do Lineamento Patos é trifurcada, com o ramo principal chegando à linha de costa ao norte de João Pessoa (observação recente, inédita ainda). Neste ramo principal e nos subsidiários que para o norte transectam o RGND, a formação de rochas cataclásticas e miloníticas é expressiva, chegando a dezenas de quilômetros, em condições de elevada temperatura e a recristalizar rochas na facies granulito. Notável associação desses ramos do lineamento com granitóides brasilianos foi recentemente relatada por Jardim de Sá $e t$ al. (1999). Sedimentos terciários ("Serra do Martins" e equivalentes) mostram evidências de retrabalhamento no sentido vertical destas "feather faults" na porção mais oriental do Lineamento. Na porção mais ocidental, a organização estrutural das Bacias do Rio do Peixe (depocentros 
$>1000 \mathrm{~m}$ ) e do Araripe (depocentros > 2000m) estão evidenciadas também reativações mesocenozóicas para esta linha ramificada de descontinuidade litosférica, onde dois contextos geológicos distintos estão contíguos.

No lado brasileiro, vários dados $\mathrm{Sm}-\mathrm{Nd}$ em rochas ao sul e ao norte da parte principal do lineamento de Patos ainda inéditos - mostram que se tratam de contextos geológicos bastante distintos que estão sendo separados: ao norte, os valores Tdm são geralmente arqueanos e paleoproterozóicos (mesmo aqueles de granitóides brasilianos) com dados de $\mathcal{E N d}$ fortemente negativos; ao sul, os valores Tdm costumam ser do paleoproterozóico superior e mesoproterozóico (a maioria) e os dados de $\varepsilon \mathrm{Nd}$ são negativos, mas não fortemente.

Mais ao sul (ca. 200Km), quase que paralelo ao Lineamento de Patos (Garoua) fica o Lineamento de Pernambuco (Adamaoua-Ngaoundéré), clássica zona de cisalhamento destral (como o de Patos), marcando assim o domínio da Zona Transversal da PB. Deve-se falar numa entidade estrutural maior, o "Median Shear Corridor" (designação de Trompette, 1994, Figura 7) dentro de Gondwana, de forma mais ou menos retangular, gerado pela tectônica extrusional e expressando fuga sub-equatorial de massas (escape tectonics) na fase final do PBA. Durante todo o Fanerozóico este esquema complexo de zonas de cisalhamentos (onde são muito comuns falhas adventícias em ângulo forte -NNE-SSW - para acomodar os deslocamentos das mestras subparalelas - EW) influi na geração, distribuição e arranjo e estruturação de bacias sedimentares. A ligação da extremidade oriental do Lineamento Pernambuco (conhecido na margem continental no paralelo de Recife) com a Zona de Adamoua-Ngaunderé (que coincide/condicionou com o lineamento vulcânico terciário dos Camarões) é uma constatação muito antiga, desde os primeiros trabalhos de correlação (e. g. Almeida, 1965), seguida por inúmeros pesquisadores. E a definição do "median shear corridor" foi muito feliz, em observação e propósito, e deveria ser evocada sempre doravante.

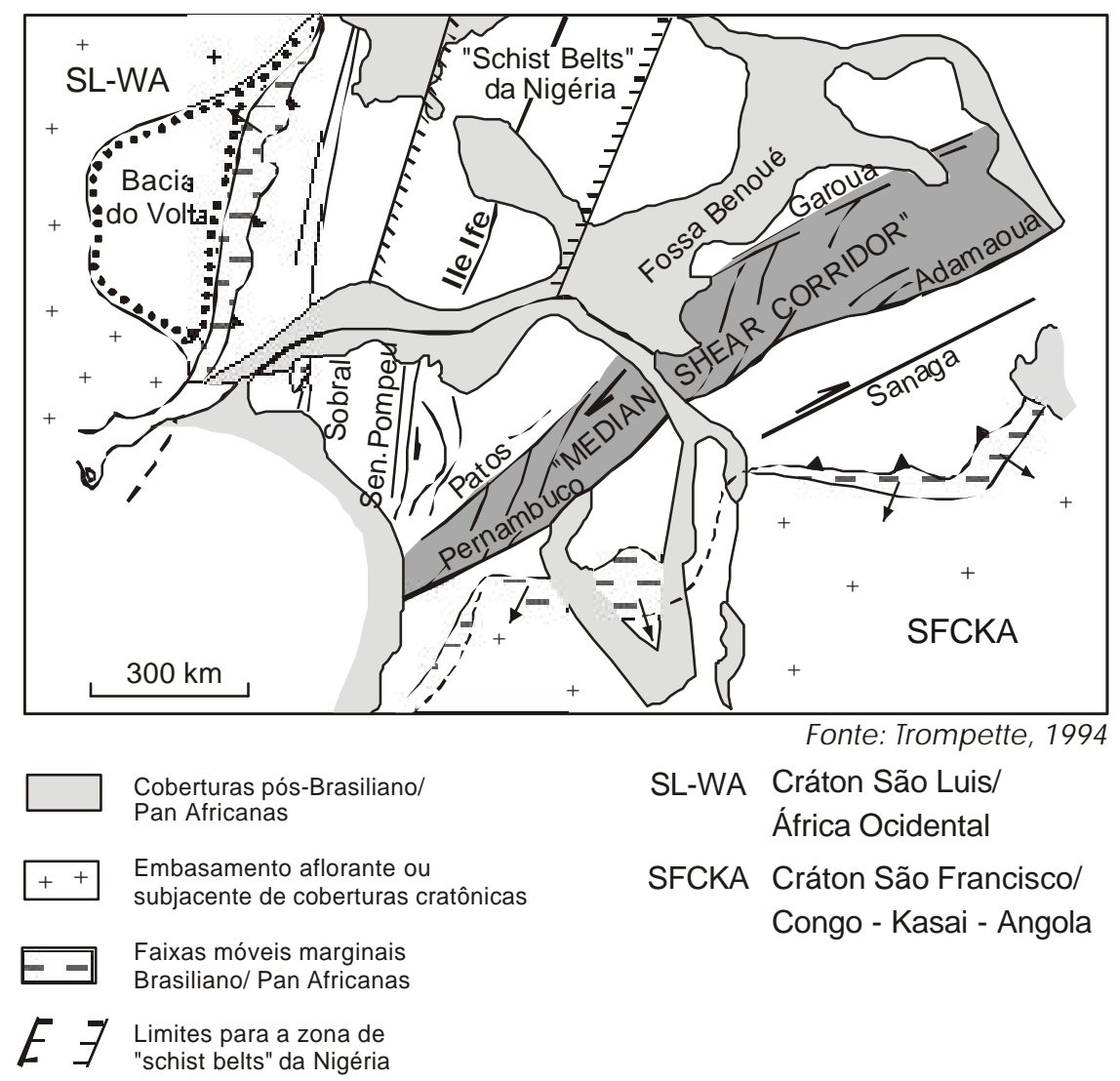

Figura 7: O "Median Shear Corridor" conforme sugerido por Trompette (1994). Ênfase para os lineamentos Patos-Garoua (ao norte) e Pernambuco-Ngaoundéré/Adamoua (ao sul). A faixa móvel Trans-Sahara também é mostrada, a oeste do lineamento Kandi $\left(4^{\circ} 50\right)$ - Transbrasiliano mostrado como um único, na assunção de correlação. É possível que os lineamentos de Ile-Ife e Senador Pompeu também estejam em continuidade. 


\section{Exercício de Correlação}

A identificação desta zona transversal comum aos dois continentes traz outros problemas à tona, sendo agora destacados algumas diferenças marcantes, problemas em aberto para investigação posterior.

No lado brasileiro, a zona transversal é marcada pelo amálgama de terrenos vulcano-sedimentares e Neoproterozóicos (Orogenia Cariris Velhos, Terreno Alto Pajeú- TAP, Brito Neves et al. 2000) e Neoproterozóicos (PAB = Piancó Alto Brígida, $\mathrm{RC}=$ Rio Capibaribe, Brito Neves et al., 2000) com exposições locais de altos estruturais do embasamento, que se mostrou semelhante àquele da colagem paleoproterozóica, descrita anteriormente.

No lado africano, a preservação de supracrustais é raridade, merecendo destaque o "Poli Series" ou grupo (nas imediações sul do lineamento Garoua /Patos), a cerca de $700 \mathrm{~km}$ da linha de costa, onde se encontram seqüências meta-vulcano-sedimentares de baixo grau de idade neoproterozóica (entre 830 e $750 \mathrm{Ma}$ ). Estas raras supracrustais preservadas, de ambiente de retroarco de embasamento ensiálico (paleoproterozóico) são as únicas que podem ser utilizadas para correlação (mais para comparação) com aquelas do lado brasileiro, que no caso seriam as do Sistema Piancó-Alto Brígida.

Tirante esta exceção da "série Poli", predominam rochas de alto grau (mesmo sendo rochas do Neoproterozóico, da evolução de BPA), não há uma só evidência de rochas eo-neoproterozóicas do Ciclo Cariris Velhos (Brito Neves et al., 2000), nem das supracrustais do terreno Rio Capibaribe (RC, Faixa "Surubim Caroalina"), que dominam em exposição franca na parte mais oriental da Zona Transversal no Brasil, e que alcançam diagonalmente à linha de costa. Tanto no "median shear corridor" como ao sul dele, no domínio pericratônico ao SFCKA, na África, são comuns rochas neoproterozócias da fácies granulito (absolutamente desconhecidas no Brasil até o presente).

Diante dessas constatações acima, no momento atual do conhecimento, a única afirmação possível é no lado africano estão expostos contextos de nível crustal mais profundo, por razões de diversas, talvez de maior rigor de exumação e/ou soerguimento. Se isto é fato, e a idade destes processos mais rigorosos (no Fanerozóico) em África são problemas em aberto.

Outro aspecto interessante de distinção na história Fanerozóica é a expressividade em área de vulcanismo básico Terciário no lado africano (vide mapa de Benkhelil, 1989) por todo o "median corridor", da linha vulcânica dos Camarões para o norte até as imediações de Adamoua, como já previamente adiantado. E isto é um argumento a favor de que o soerguimetno em África foi pré-Cenozóico. No lado brasileiro, o magmatismo terciário está restrito a alguns poucos centros de pequena magnitude (até o presente momento do conhecimento).

\section{O Segmento Meridional da Colagem Brasiliano Pan Africano (BPA)}

\section{- As faixas móveis peri-SFCKA}

A porção imediatamente ao norte do SFCKA apresenta um contexto de margem continental neoproterozóica mais ou menos contínua e rastreável e que foi desenvolvida sobre o embasamento da colagem do Paleoproterozóico (a qual incluiu alguns "seed nuclei" arqueanos). Da fronteira Bahia-Piauí (Rio Preto) para o sudoeste de Pernambuco (Riacho do Pontal) e sul de Sergipe-nordeste da Bahia (Sergipano), este desenvolvimento apresenta sempre uma dualidade de sequiências tectono-estratigráficas, sendo uma mais antiga (maior contingente psamíticopelitico) e outra pelítico carbonática com interveniências basais glaciais, passível de ser incluída no amplo contexto do Supergrupo São Francisco.

No continente africano os mesmos desenvolvimentos são reconhecidos, de oeste (leste dos Camarões) para leste (Zaire), ainda que sob uma enorme diversidade de designações e detalhes locais, o que foi sumulado como Faixa Oubanguides por Trompette (1994), cabendo a este autor ratificar a correlação com a porção brasileira. Assim sendo as sequiências descritas de oeste para leste na África como Mbalmayo Bengbis-Ayos, Dja e Sembe Ouesso, Nola, Bangui (estas duas compondo uma unidade estratigráfica inferior) e Fouroumbala parecem compor a parcela proximal da margem continental, e que foi transformada em faixa móvel, apresentando deformação variada, metamorfismo (incipiente a grau baixo), empurrões e descolamentos voltados para o sul, para o SFCKA. Apesar da fragmentação (erosional sobretudo) do registro (e outros fatores geográficos mais que geológicos de fronteiras), as semelhanças litoestratigráficas são muitas com aqueles dos contextos Miaba/Vaza Barris, Grupo Chapada Diamantina/Casa Nova; Rio Preto/Supergrupo S. Francisco, embora o controle geocronológico seja de pequena monta em ambos os continentes. Verificar que mesmo no Brasil (diversidade política e geográfica menor), a profusão de nomes ocorre no trato de um mesmo contexto de margem continental, quando ele se estende por mais de uma fronteira estadual.

$\mathrm{Na}$ porção mais distal da faixa (e aproximada por 
tectonismo), nos Camarões, com estruturas vergentes para o cráton, ocorre extensivamente a "Yaoundé séries" (Toteu et al., 1995) composta por rochas metamórficas de alto grau, granada-xistos e gnaisses e migmatitos, afetada por intenso plutonismo, com pelo menos dois estágios deformacionais importantes, estando em parte alóctonas sobre o núcleo cratônico ao sul. Mais para leste, na República Central Africana, ocorrem rochas na fácies granulítica (orto e paraderivados) que forneceram idades na faixa de ca. 830 e ca. 650-630 Ma (Pin \& Poidevin, 1987).

No lado brasileiro, estas porções mais distais destes sistemas orogênicos do norte do SFCKA são ocupadas por espessas sequiências vulcano-sedimentares de médio grau (quartzitos, granada-micaxistos, metavulcânicas ácidas), que afloram amplamente sob a designação informal de Grupo ou Complexo Macururé (e/ou MarrrancóCanindé). Há ainda nestas porções mais distais uma possibilidade em aberto da ocorrência inclusive de restos de seqüências desenvolvidas em assoalho oceânico (várias indicações geoquímicas e petrológicas preliminares, carecendo aprofundamento), no Riacho do Pontal (Unidade Monte Orebe) e no Sergipano (Unidade Canindé do São Francisco).

Novamente, ficam evidentes exposições de níveis crustais mais profundos na contraparte africana, para os tratos distais, como uma diferença significativa. Podem ser adicionalmente consideradas diferenças dignas de registro a presença de vulcanismo fissural básico toleítico no Grupo Bakouma, da parte mais superior dos metassedimentos Oubanguides (incomum nos Sistemas Sergipano e Rio Preto, e raro no Riacho do Pontal) e a presença de rochas da fácies eclogito no Grupo Bangui.

\section{CONSIDERAÇÕES FINAIS}

O exercício de correlação da Província Borborema e seus núcleos cratônicos delimitantes com aqueles homólogos do noroeste africano é plenamente factível, e auferiu/evoluiu bastante do acervo de conhecimentos surgidos na última década, principalmente oriundos de uma série de teses de doutoramentos e outros de sínteses objetivas.

Há uma série de problemas em aberto ainda, crescentes com a escala de observação, cuja superação se espera com o avanço natural e esperado do conhecimento. Nas grandes escalas de reconhecimento, muitos destes problemas têm sido omitidos ou nem chegam a aflorar devidamente. Na escala de detalhe, em todos os segmentos considerados lado a lado, de norte para o sul na busca de correlação, aparecem semelhanças interessantes e alguns pro- blemas, entre já conhecidos e outros novos. Alguns destes são realmente problemas geológicos de fato, consistentes, demandando direcionamento (pré-programado) na pesquisa e alvo bem definido.

$\mathrm{Na}$ porção mais a oeste do lineamento KandiTransbrasiliano persistem vários problemas. Muitos dos registros da evolução de uma margem continental (de passiva a colisional) consignados em África (e resumidos por Caby, 1998) não estão presentes no Médio Coreaú, no Ceará, uma área conhecida na escala de detalhe. A alusão que aqueles registros tão bem expostos na África estariam sotopostos aos sedimentos fanerozóicos não vem encontrando o devido respaldo nos levantamentos geofísicos. Uma investigação mais acurada se faz necessário, inlcuindo-se aí a busca pelos agentes responsáveis destas defecções, de supressão erosiva a extrusão pós-colisional ou de ambos.

Na porção imediatamente a leste do lineamento KandiTransbrasiliano há algumas diferenças nos registros geológicos e geocronológicos, alguns dos quais podem ser colocados na cota de insuficiência de dados, tendo em vista o nível de reconhecimento dos estudos até agora. Assim, os eventos de ca. 2150 Ma do embasamento paleoproterozóico, ocorrente por excelência no lado brasileiro (no RGND), não tem ainda a correspondência esperada nas zonas equivalentes de escudo no lado africano. Da mesma forma que os eventos de orogenias precoces do Neoproterozóico bem registrados na África $(0,87$ $\mathrm{Ga} ; 0,84 \mathrm{Ga} ; 0,75-0,740 \mathrm{Ga}$ ) ainda não foram detectados no lado brasileiro (são possíveis e há alguns sinais neste sentido).

Neste contexto - a leste do Kandi-Transbrasiliano e a norte do "median shear corridor" - uma diferença interessante de se destacar é que o expressivo desenvolvimento do sistema Seridó, área clássica da Borborema, não pode ser claramente identificado na contraparte africana. Entre os muitos "schist belts" nigerianos podem estar alguns que correspondam ao Seridó, mas os dados geológicos e geoeconômicos disponíveis dos dois continentes parecem bastante distintos, e este tipo de equiparação é insatisatório.

Neste caso, devem ser evocadas ainda como óbices adicionais à correlação tanto a dissecação erosiva (mais contundente na África) quanto as coberturas cenozóicas do Delta do Niger que encobrem grandes áreas (e fizeram progradar a linha de costa).

No "median shear corridor", entre os lineamentos Patos-Garoua e Pernambuco-Ngaounderé persiste uma grande dificuldade de correlação. No lado africano faltam (até o momento) registros de toda a evolução do Ciclo Cariris Velhos e de seus principais elementos (terrenos Alto Pajeú, Alto Moxotó e Rio Capibaribe). Adicionalmente a repre- 
sentação lito-estratigráfica das supracrustais neoproterozóicas é extremamente rarefeita no contexto africano (diferentemente do caso da Borborema). Tratase de uma diferença fundamental, carecendo pesquisa dirigida, mas que também volta a evocar as diferenças na evolução geomórfica dos dois continentes.

Nas faixas móveis proximais e distais - da periferia norte do cráton SFCKA, há algumas diferenças de geologia básica, aceitáveis e esperáveis em tão longo contexto de margem continental. Mas no tocante a natureza dos registros, eles são excepcionais no lado brasileiro (níveis crustais rasos sobretudo), em preservação e conteúdo, e são absolutamente fragmentários do lado africano, com exposição de níveis crustais profundos. E isto traz dificuldades eventuais aos exercícios de correlação.

Ao se analisar o quadro de preservação dos registros geológicos pré-cambrianos, nos dois continentes verificase que gradativamente isto assoma feições de um problema geológico de vulto, a ser enfrentado. Apenas no Domínio Médio Coreaú do noroeste do Ceará (a oeste do Kandi-Transbrasiliano) a dissecação erosiva aparenta ser mais intensa na contraparte brasileira, posto que em todos demais domínios do PBA na África, a tônica é de arrasamentos importantes, feições vestigiais, exposição de níveis crustais mais profundos etc..

Outro aspecto interessante (e de diferença) é a forma e extensividade com que a contraparte africana foi privilegiada por plutonismo e vulcanismo meso-cenozóico, registros que podem ser considerados relativamente escassos no lado brasileiro. No Brasil, temos apenas um registro de granito anorogênico eocretácico, consorciado com vulcanismo importante (no Cabo Santo Agostinho, ao sul do Recife, na continuação provável da linha vulcânica dos Camarões). No Brasil, o vulcanismo terciário é caracteristicamente esparso em área e modesto em proporções ("Vulcanismo/Formação Macau"), no Rio Grande do Norte e Paraíba e nas imediações de Cubati-PB, Mulungu-PB, Boa Vista-PB, Itabaiana-PB, sempre ocorrências discretas), sendo exuberante na contraparte africana. Adicionalmente, como estas rochas ígneas recortam supracrustais do Cariris Velhos e do Brasiliano, significa que as condições da geodinâmica das duas placas persistiram diferentes (preservação das supracrustais no lado brasileiro, maior intensidade do magmatismo no lado da África) por todo o Fanerozóico.

O equacionamento adequado para todos estes problemas (evolução fanerozóica inclusive) só pode advir da investigação geológica previamente dirigida ou arbitrada, por grupos multidisciplinares de investigação, de preferência sob o "guarda-chuva" de um IGCP da UNESCO ou assemelhado. Se a correlação (demonstração de equiva- lência tectônica e estratigráfica) continuar da forma livre e generalista como costuma acontecer, o caminho será bastante longo. Embora tenham sido constatados alguns pontos de dissensão, em campos distintos do conhecimento, não parece haver problemas insuperáveis, desde que a escala (adoção de escalas maiores) e a forma de análise (trabalho em equipes multidisciplinares dos dois continentes) sejam modificadas para contextos mais adequados.

\section{AGRADECIMENTOS}

O trabalho de pesquisa do autor sênior (BBBN) foi subsidiado em várias etapas pela FAPESP (Fundação de Amparo á Pesquisa do Estado de São Paulo) e pelo CNPq. Os demais autores (WRVS, AHF) receberam subsídios do National Science Foundation (EAR 9117594, 9316047 e 9614473) e do Departamento de Geologia da Universidade do Kansas. A todas estas entidades são expressos nossos melhores agradecimentos.

\section{REFERÊN CIAS BIBLIOGRÁFICAS}

AFFATON, P. (1990) Le bassin des Volta (Afrique de L'Ouest): une marge passive d' âge Proterozoïque Superieur, tectonisée au Panafricain (600(50 Ma). Marseille, 2v. (Ph. D. Thesis) - Université dÁix Maerseille III.

AJIBADE, A. C.; WRIGHT, J. B. (1989) The Togo-BeninNigerian Shield: evidence of crustal aggregation in the Pan-African belt. Tectonophysics, v. 165, n. 1-4, p.125-129.

AJIBADE, A. C.; WOAKES, M.; RAHAMAN, M. A. (1987) Proterozoic crustal development in the PanAfrican Regime of Nigeria. In: KRONER, A. (ed.) Proterozoic lithospheric evolution. Washington, American Geophysical Union. p. 259-271. (Geodynamics Series, v. 17)

ALMEIDA, F. F. M. (1965) Precambrian geology of Northeastern Brazil and Western Africa and the theory of continental drift. In: SYMPOSIUM ON THE GRANITES OF WEST AFRICA, Paris, 1965. Proceedings. Paris, UNESCO. p. 151-162. (Natural Resources Research, VIII, Special Report n. 4, Circul. Restrita).

ALVARENGA, C. J. S.; MOURA, C.A.V.; GORAYEB, P. S. S.; ABREU, F. M. (2000) Paraguay and Araguaia Belts. In: CORDANI, U. G.; MILANI, E. J.; THOMAZ FILHO, A. CAMPOS, D. A. (eds) Tec- 
tonic Evolution of South America. INTERNATIONAL GEOLOGICAL CONGRESS, 31, Rio de Janeiro. p. 183-194.

ARTHAUD, M.H.; VASCONCELLOS, A. M.; OLIVEIRA, F. V.C. (1998). As seqüências metassedimentares do Ceará Central. In: CONGRESSO BRASILEIRO DE GEOLOGIA, 40., Belo Horizonte, 1998. Anais. Belo Horizonte, SBG. v. 1 , p.16.

BENKHELIL, J. (1989) The origin and evolution of the Cretaceous Benoue Trough (Nigeria). Journal of African Earth Sciences, v. 8, n. 2-4, p. 251-282.

BERTRAND, J. M. L.; CABY, R.; DUCROT, J.; LANCELOT, J. POUCHKINE, A. M.; SAADALLAH, A. (1978) The Late Pan African intracontinental fold belt of the Eastern Hoggar ( Central Sahara, Algerie): Geology, structural development, U/Pb geochronology, tectonic implication for the Hoggar Shield. Precambrian Research, v. 7, p. 349-376.

BERTRAND, J. M.; CABY, R. (1978) Geodynamic evolution of the Pan-African orogenic belt: a new interpretation of the Hoggar Shield (Algerian Sahara). Geologische Rundschau, v. 67, n. 2, p. 357-388.

BITTAR, S. M. B. (1999) Faixa Piancó-Alto Brígida: terrenos tectono-estratigráficos sob regimes metamórficos e deformacionais contrastantes. São Paulo, 135 p. (Tese-Doutorado) - Instituto de Geociências, Universidade de São Paulo.

BLACK, R.; BAMAKO, H.; BALL, E.; BERTRAND, J. M .; BOULLIER, A M.; CABY, R.; DAVISON, I.; FABRE, J.; LEBLANC, M. (1979) Outline of the Pan-African Geology of Adrar des Iforas ( Republic of Mali). Geologische Rundschau, v. 68, p. 543-564.

BRITO NEVES, B. B.; VAN SCHMUS, W. R.; SANTOS, E. J.; CAMPOS NETO, M. C.; KOZUCH, M. (1998) The Cariris Velhos events; a Grenvillian Orogenesis in the northeastern part of South America. Journal of African Earth Sciences, v. 27, n. 1A, p.38.

BRITO NEVES, B.B.; CAMPOS NETO, M. C.; FUCK, R. A (1999) From Rodinia to Western Gondwana: an approach to the Brasiliano-Pan-African Cycle and orogenic collage. Episodes, v. 22, n. 3, p. 155-166.

BRITO NEVES, B. B.; VAN SCHMUS, W. R.; SANTOS, E. J. (1999) Cariris Velhos Plutonism: a Grenvillian Age (Rodinian) collisional zone or a rift zone in northeast South America. In: HUTTON SYMPOSIUM THE ORIGIN OF GRANITES AND RELATED ROCKS, Clermont-Ferrand, 1999. Abstracts. Clermont-Ferrand, p.134.
BRITO NEVES, B. B.; SANTOS, E. J.; VAN SCHMUS, W. R. (2000) Tectonic history of the Borborema Province. In: CORDANI, U. G. ; MILANI, E. J. ; THOMAZ FILHO, A. ; CAMPOS, D.A. (eds) Tectonic Evolution of South America. INTERNATIONAL GEOLOGICAL CONGRESS, 31., Rio de Janeiro, p. 151-182.

BRUGUIER, O.; DADA, S.; LANCELOT, J. R. (1994) Early Archean component ( > 3.5 Ga) within a 3.05 Ga orthogneiss from northern Nigeria: U-PB zircon evidences. Earth and Planetary Sciences Letters , v. 125 , n. $1-4$, p. $89-103$.

CABY, R.; ANDREOPOULUS-RENAUD, U.; GRAVELLE, M. (1982). Cadre géologique et géochronologie $\mathrm{U} / \mathrm{Pb}$ sur zircon des batholites précoces dans le segment pan-africain du Hoggar central (Algérie). Bulletin Societé Geologique de France. Serie 7, v. 24, n. 4, p. 677-684.

CABY, R.; BERTRAND, J . M.; BLACK, R. (1981) PanAfrican ocean closure and continental collision in the Hoggar-Iforas Segment, Central Sahara. In: KRÖNER, A. (ed.) Precambrian plate tectonics. Amsterdam, Elsevier. p. 407-431

CABY, R. (1989) Precambrian terranes of Benin - Nigeria and Northeast Brazil and the Late Proterozoic South Atlantic fit. Geological Society of America. Special Paper, v. 230, p.145-158.

CABY, R. (1998) Tectonic History and Geodynamic Evolution of Northern Africa during Neoproterozoic. In: INTERNATIONAL CONFERENCE ON PRECAMBRIAN AND CRATON TECTONICS / INTERNATIONAL CONFERENCE ON BASEMENT TECTONICS, 14, Ouro Preto, 1998. Abstracts. Ouro Preto, Universidade Federal de Ouro Preto, p. 72-75.

CASTAING, C.; TRIBOULET, C.; FEYBESS, J. L.; CHÈVREMONT, P. (1993) Tectonometamorphic evolution of Ghana, Togo and Benin in the light of the Pan-African/Brasiliano orogeny. Tectonophysics, v. 218, p. 323-342.

DADA, S. S. (1998) Crust-forming ages and Proterozoic crustal evolution in Nigeria: a reappraisal of current interpretations. Precambrian Research, v. 87, p. 65-74.

DALLMEYER, R. D. (1989) Contrasting accreted terranes in the Southern Appalachian orogen, basement beneath the Atlantic and Gulf Coastal Plains and West African orogenes. Precambrian Research, v. 42, p. 387-409. 
DANTAS, E. L. (1997) Geocronologia U-Pb e Sm-Nd de Terrenos Arqueanos e Paleoproterozóicos do maciço Caldas Brandão, NE do Brasil. Rio Claro, 229 p. (Tese Doutorado) - Universidade Estadual Paulista.

DEYNOUX, M.; TROMPETTE, R.; CLAUER, N. (1978) Upper Precambrian and Lowermost Palaeozoic correlations in West Africa and in the Western Part of Central Africa. Porbable diachronism of the Lte Precambrian tillite. Geologische Rundschau, v. 67, n. 2, p. 615-630.

FERRÉ, E. C.; CABY, R.; PEUCAT, J. J.; CAPDEVILA, R.; MONIÉ, P. (1998) Pan-African, post-collisional, ferro-potassic granite and quartz-monzonite plutons of Eastern Nigeria. Lithos, v. 45, p. 255-279.

FETTER, A. H. (1999) U/Pb and Sm/Nd geochronological constraints on the crustal framework and geological history of Ceará state, NW Borborema Province, NE Brazil: implications for the assembly of Gondwana. Kansas, 164 p. PhD. Thesis - University of Kansas.

GOODWIN, A. M. (1991) Precambrian geology. San Diego, Academic Press. 666 p.

HASUI, Y.; ABREU, F. A. M.; NOBRE VILLAS, R. N. 1984. Província Parnaíba. In: ALMEIDA, F. F. M. de ; HASUI, Y. (cords) O Pré-Cambriano do Brasil. São Paulo, Edgard Blücher Ltda, p. 36-45.

HATCHER Jr., R. D.; WILLIAMS, H. (1986) Mechanical model for single thrust sheets and their relationships to the mechanical behavior of Orogenic Belts. Geological Society of America Bulletin, v. 97, n.8, p. 975-985.

HOWELL, D. J. (1995) Principles of terrane analysis: new applications for global tectonics. London, Chapman \& Hall. 245 p.

JARDIM DE SÁ, E. F.; TRINDADE, R. I. F.; HOLLANDA, M. H.B. M.; ARAÚJO, J. M. M.; GALINDO, A. C.; AMARO, V. E.; SOUZA, Z. S.; VIGNERESSE, J. L.; LARDEAUX, J. M. (1999). Brasiliano Syntectonic Alkaline Granites Emplaced in a Strike Slip/Extensional Setting (Eastern Seridó Belt, NE Brazil. Anais da Academia Brasileira de Ciências, v. 71, n. 1, p. 17-28.

LÉCORCHÉ, J. P.; DALLMEYER, R. D.; VILLENEUVE, M. (1989) Definition of tectonostratigraphic terranes in the Mauritanide, Bassaride and Rokelide orogens, West Africa. Geological Society of America. Special Paper, v. 230, p. 131-144.

LEDRU, P. N.; DONG, J. E.; JOAN, V.; PRIAN, J.P.; COSTE,
B.; HACCARD, D. (1989) Structural and Metamorphic Evolution of the Gabon Orogenic Belt: collision Tectonics in the Lower Proterozoic? Precambrian Research, v. 44, p. 227-241.

LESQUER, A; BELTRÃO, J. F.; ABREU, F. M. (1984) Proterozoic links between northeastern Brazil and West Africa: a plate tectonic model based on gravity data. Tectonophysics, v. 110, p. 9-26.

MAGINI, C.; SANTOS, T. S.; BRITO NEVES, B. B.; HACKSPACHER, P. C. VAN SCHMUS, W. R.; DANTAS, E. J.; FETTER, A. H. 1999. Statherian taphrogenesis in the Borborema Province, NE Brazil. In: Simpósio Sudamericano de Geologia Isotópica, 2/South American Symposium on Isotope Geology, 2., Córdoba, 1999. Actas. Córdoba, SEGEMAR, p. 327-330.

MATOS, R. M. D. (2000) History of the northeastern Brazilian rift system: kynematic imolication for the breakup between Brazil and Africa. In: CAMERON, N. R.; BATE, R. H.; CLURE, V. S. (eds.) The oil and gas habitats of the South Atlantic. London, Geological Society, p. 55-73 (Geological Society Special Publication, v. 153).

NUNES, K. C. (1993) Interpretação integrada da Bacia Parnaiba com ênfase nos dados aeoromagnéticos. In: CONGRESSO INTERNACIONAL DA SOCIEDADE BRASILEIRA DE GEOFÍSICA, 3., Rio de Janeiro, 1993. Resumos Expandidos. Rio de Janeiro, SBGf. v. 1, p.152-156.

PIN, C.; POIDEVIN, J. L. (1987) U-Pb zircon evidences for a Pan-African granulite facies metamorphism in the Central African Republic. A new interpretation of the high-grade series of the northern border of the Congo Craton. Precambrian Research, v. 36, p. 303-312.

POPOFF, M. (1988) Du Gondwana à l'Atlantique Sud: les connexions du fossé de la Benoué avec les bassins du Nort-Est brésilien jusquá l' ouverture DU GOLFE DE Guinée au Cretacée Infereur. Journal of African Earth Sciences, v. 7, n. 2, p. 409-431.

RAMOS, V. V. 1988. Tectonics of the Late ProterozoicEarly Paleozoic; a collisional history of southern South America. Episodes, v. 11, n.3, p. 168-174.

RAPELA, C. W.; PANKHURST, R. J.; CASQUET, C; BALDO, E.; SAAVEDRA, J. GALINDO, C. (1998) Early evolution of the Proto-Andean margin of South América. Episodes, v. 26, n. 8, p. 707-710.

ROGERS, J. J. W. (1996) A history of the continents in the 
past three billions of years, Journal of Geology, v. 104, p. 1405-1412.

SANTOS, E. J. (1995) O complexo granítico Lagoa das Pedras: acresção e colisão na região de Floresta (Pernambuco), Província Borborema. São Paulo, 220p. (Tese-Doutorado) - Instituto de Geociências, Universidade de São Paulo.

SANTOS, T. J. S. (1999) Evolução tectônica geocronológica do extremo noroeste da Província Borborema. Rio Claro, 295p. (Tese-Doutorado) Universidade Estadual Paulista.

TORQUATO, J. R; CORDANI, U. G. (1981) Brazil-Africa Geological Links. Earth Science Reviews, v. 17, p.155-176.

TOTEU, S. F.; MICHARD, A.; BERTRAND, J. M.; ROCCI, G. (1987) U/Pb dating of Precambrian rocks from northern Cameroon, orogenic evolution and chronology of the Pan-African Belt of central Africa. Precambrian Research, v. 37, p. 71-87.

TOTEU, S. F.; VAN SCHMUS, W. R.; PENAYE, J.; NYOBÉ, J. B. (1995) U-Pb and Sm-Nd evidence for Eburnian and Pan-African high grade metamorphism in cratonic rocks of Southern Cameroon. Precambrian Research, v. 67, p.321-347.

TOTEU, S. F.; VAN SCHMUS, W. R.; PENAYE, J.; MICHARD, A. (2000). New U-Pb and Sm-Nd data from the north-central Cameroon and its bearing on the pre-Pan-African history of Central Africa. Precambrian Research, v. 108, n. 1-2, p. 45-73.

TROMPETTE, R. (1994) Geology of Western Gondwana. Rotterdam, A. A. Bakelma. 350 p.

TURNER, D. C. (1983) Upper proterozoic schist belts in Nigerians Sector on the Pan-African Province of west Africa. Precambrian Research, v. 21, p. 55-79.

VAN SCHMUS, W. R.; BRITO NEVES, B. B.; HACKSPACHER, P. C.; BABINSKI, M. (1965) U/ $\mathrm{Pb}$ and $\mathrm{Sm} / \mathrm{Nd}$ geochronologic studies of eastern Borborema Province, Northeast Brazil; initial conclusions. Journal of South American Earth Sciences, v. 8, n. 3-4, p. 267-288.

VILLENEUVE, M.; DALLMEYER, R. D. (1988) Geodynamic evolution of the Mauritanide, Bassaride, and Rokelide orogens (West Africa). Precambrian Research, v. 37, p. 19-28 